\title{
Quality of life evaluation in Mexican patients with severe obesity before and after bariatric surgery
}

\author{
Alejandra Albarrán-Sánchez, ${ }^{1}$ Claudia Ramírez-Rentería, ${ }^{2}$ Aldo Ferreira-Hermosillo, ${ }^{2 *}$ \\ Víctor Rodríguez-Pérez, ${ }^{3}$ Etual Espinosa-Cárdenas, ${ }^{1}$ Mario Molina-Ayala, ${ }^{1}$ Ilka Boscó-Gárate ${ }^{4}$ and \\ Victoria Mendoza-Zubieta ${ }^{1}$ \\ ${ }^{1}$ Endocrinology Department, Specialty Hospital, Centro Médico Nacional Siglo XXI, Instituto Mexicano del Seguro Social; ${ }^{2}$ Endocrine Diseases \\ Medical Research Unit, Specialty Hospital, Centro Médico Nacional Siglo XXI, Instituto Mexicano del Seguro Social; ${ }^{3}$ Antiretroviral Adherence and \\ Polypharmacy Clinic, Clínica Especializada Condesa; ${ }^{4}$ Immunochemistry Medical Research Unit, Specialty Hospital, Centro Médico Nacional Siglo \\ XXI, Instituto Mexicano del Seguro Social. Mexico City, Mexico
}

\begin{abstract}
Introduction: In Mexico, neither the 36-item Short Form Health Survey (SF-36) nor the Bariatric Analysis and Reporting Outcome System (BAROS) instruments have been used to assess quality of life (QoL) before and after bariatric surgery (BS). Objective: To describe changes in QoL using the SF-36 and BAROS questionnaires in patients with severe obesity before and after BS. Methods: Clinical and anthropometric data of patients undergoing bariatric surgery between 2015 and 2016 were collected. Statistical significance was considered with a p-value $<0.05$. Results: 230 patients were analyzed, 98 before and 132 and after BS; most were females (81\%). Initial body mass index was $48 \mathrm{~kg} / \mathrm{m}^{2}$ (44-53). SF-36-measured QoL showed an increase in the physical component score from 43 to 54.2 points $(p<0.001)$, and in the mental component, from 53.3 to 56.6 points after BS. With BAROS, $98.5 \%$ showed good to excellent QoL results within the first three months after BS. Conclusion: When measured with the SF-36 and BAROS questionnaires, QoL of Mexican patients with severe obesity was found to improve after BS.
\end{abstract}

KEY WORDS: Obesity. Quality of life. Questionnaire. Bariatric surgery.

\section{Evaluación de la calidad de vida en pacientes mexicanos con obesidad severa antes y después de cirugía bariátrica}

\section{Resumen}

Introducción: En México no se han utilizado los instrumentos Shorth Form 36 Items (SF-36) ni Baryatric Assesment Reporting Outcomes System (BAROS) para evaluar la calidad de vida (CV) antes y después de la cirugía bariátrica (CB). Objetivo: Describir los cambios en la CV con los cuestionarios SF-36 y BAROS, en pacientes con obesidad severa antes y después de la CB. Métodos: Se recolectaron los datos clínicos y antropométricos de pacientes sometidos a cirugía baríatrica entre 2015 y 2016. Se consideró con significación estadística una $p<0.05$. Resultados: Se analizaron 230 pacientes, 98 y 132 antes y después de la CB; la mayoría fue del sexo femenino (81\%). El índice de masa corporal inicial fue de $48 \mathrm{~kg} / \mathrm{m}^{2}$ (44-53). La CV medida con el SF-36 demostró un incremento en la puntuación del componente físico de 43 a $54.2(p<0.001)$ y en el componente mental, de 53.3 a 56.6 después de la CB. Con BAROS, en $98.5 \%$ se registraron resultados buenos a excelentes en la CV en los primeros tres meses. Conclusión: Al ser medida con los cuestionarios SF-36 y BAROS se definió que la CV de los pacientes mexicanos con obesidad severa mejora después de la CB.

PALABRAS CLAVE: Obesidad. Calidad de vida. Cuestionario. Cirugía bariátrica.

Correspondence:

*Aldo Ferreira-Hermosillo

E-mail: aldo.nagisa@gmail.com
Gac Med Mex. 2021;157:64-69

Contents available at PubMed

www.gacetamedicademexico.com

0016-3813/С 2020 Academia Nacional de Medicina de México, A.C.. Published by Permanyer. This is an open access article under the CC BY-NC-ND license (http://creativecommons.org/licenses/by-nc-nd/4.0/). 


\section{Introduction}

The World Health Organization reports that $3 \%$ of the Mexican population has severe or morbid obesity, defined as a body mass index $\left(\mathrm{BMI}, \mathrm{kg} / \mathrm{m}^{2}\right)$ higher than $40 \mathrm{~kg} / \mathrm{m}^{2}{ }^{1,2}$ Bariatric surgery $(\mathrm{BC})$ it is the only treatment for severe obesity that has achieved a significant and constant weight reduction in the medium term and that manages to control obesity-associated diseases. ${ }^{3}$ Increased BMI is related to a lower quality of life (QoL). There is insufficient information on the effect of bariatric surgery on QoL in the Mexican population.-6

Measuring quality of life is not easy, and there are several instruments to do it. The Bariatric Assessment Reporting Outcomes System (BAROS) questionnaire is a simple, validated and specific instrument for patients who underwent bariatric surgery, which evaluates surgery success according to excess weight loss, as well as to improvement in comorbidities and quality of life..$^{6-8}$ Favretti et al. ${ }^{9}$ reported good to excellent results in $48 \%$ of the population, while Velásquez Zambrano ${ }^{10}$ recorded excellent results within the first six months after bariatric surgery in $31.7 \%$ of patients and in $42.9 \%$ at three years. ${ }^{8,9}$

The Short Form-36 Health Survey (SF-36) is the general quality of life measurement instrument that is most widely used in the world and is validated in the Mexican population as well. It is self-administered and is scored on a 0 to 100 scale, where a higher score means better quality of life..$^{11,12}$ After bariatric surgery, an improvement has been shown to exist, mainly in the physical component; however, there is limited information in Mexico. 5,13-15

The purpose of the study was to find out, with the SF-36 questionnaire, the QoL of a cohort of Mexican patients before and after bariatric surgery, as well as with the BAROS questionnaire after the surgical procedure.

\section{Methods}

Between February 2015 and February 2016, BC candidates $(n=98)$ who attended the Obesity Clinic, as well as subjects who were on post-surgery follow-up at different times from three months to five years $(n=132)$, were invited to participate. After reading and signing the informed consent form (registration at IMSS no. 3601 Local Health Research Ethics Committee: R-2016-3601-27), the SF-36 questionnaire was applied to all patients before and after surgery and the BAROS questionnaire after surgical intervention. Age, history of diseases, anthropometric data, and the results of the questionnaires were evaluated and recorded.

\section{Statistical analysis}

SPSS software, version 23, was used for statistical analysis. Quantitative variables were described as medians with interquartile ranges owing to their distribution. Qualitative variables were described as frequencies or percentages. For bivariate analysis, Mann-Whitney's U-test (for evaluation between two groups) or ANOVA (for three groups) were used. Qualitative variables were evaluated using the chi-square test. A p-value $<0.05$ was considered to be statistically significant.

\section{Results}

A total of 230 patients with a median age of 45 years (interquartile range $[\mathrm{IQR}]=37-50$ years) were included, out of whom $81 \%$ were women; initial weight was $142 \mathrm{~kg}$ in men and $125 \mathrm{~kg}$ in women. Initial BMI was 48 (44-53); $53 \%$ had a BMl of 40-49.9; $30 \%, 50-59.9$ (super-obesity); and $9 \%$, a BMI higher than 60 (super-super-obesity). In the overall population, the nutritional plan achieved a weight reduction from 126 to $110 \mathrm{~kg}(p<0.001)$ and the last weight recorded after bariatric surgery was $79 \mathrm{~kg}(67-93 \mathrm{~kg})$. The percentage of excess weight lost (EWL \%) during the first year after surgery was $59 \%$. As shown in table 1 , the main comorbidities prior to surgery were high blood pressure, prediabetes, diabetes mellitus, dyslipidemia, and obstructive sleep apnea. Most patients underwent laparoscopic gastric bypass.

\section{SF-36 general instrument}

Physical and mental components median summations before surgery were 43 points $(I Q R=36-50)$ and 53.3 points (IQR $=42.1-57.7)$, respectively. There were no differences between BMI strata or between genders in the pre-surgical SF-36 score. The SF-36 score increase was observed from three to 12 months after BS; there was no significant score increase after month 12 post-surgery. Differences were observed in the physical and mental components when compared before and after surgery (Table 2). Significant changes were observed in the general health and vitality areas after BS. 
Table 1. General characteristics of the population with severe obesity

\begin{tabular}{|c|c|c|}
\hline \multirow[t]{2}{*}{ Parameter } & \multicolumn{2}{|c|}{ Value $(n=230)$} \\
\hline & Median & IQR \\
\hline Age (years) & 45 & $37-50$ \\
\hline Initial weight (kg) & 126 & $113-140$ \\
\hline BMI $\left(\mathrm{kg} / \mathrm{m}^{2}\right)$ & 48 & $44-53$ \\
\hline Pre-surgical weight (kg) & 110 & $106-125$ \\
\hline EWL \% at 12 months & 59 & $54-72$ \\
\hline \multirow[t]{2}{*}{ EWL \% at 4 years } & 84 & $77-88$ \\
\hline & $\mathrm{n}$ & $\%$ \\
\hline Women & 146 & 81 \\
\hline Type 2 diabetes mellitus & 56 & 25 \\
\hline Prediabetes & 93 & 42 \\
\hline High blood pressure & 112 & 49 \\
\hline Obstructive sleep apnea & 59 & 26 \\
\hline Dyslipidemia & 76 & 34 \\
\hline Osteoarthritis & 40 & 18 \\
\hline Deep venous thrombosis & 12 & 5 \\
\hline Peripheral venous insufficiency & 37 & 17 \\
\hline Hypothyroidism & 52 & 24 \\
\hline Psychiatric disorder & 50 & 26 \\
\hline Non-alcoholic fatty liver disease & 25 & 12 \\
\hline Hyperuricemia & 24 & 12 \\
\hline Gastroesophageal reflux disease & 8 & 4 \\
\hline Vertical gastrectomy & 3 & 2 \\
\hline Roux-en-Y gastric bypass & 57 & 39 \\
\hline Gastric bypass from anastomosis & 86 & 59 \\
\hline
\end{tabular}

$\mathrm{IQR}=$ interquartile range; EWL \% = excess weight lost percentage.

Each SF-36 domain of the physical, psychological and social components and total score of patients who underwent BS, classified by baseline BMI strata, were compared with the QoL results in the general healthy population published by Zúñiga et al.:12 in all components, the score was observed to be low even after BC (Tables 3 and 4).

\section{BAROS specific instrument}

In $98.5 \%$ of the patients, good, very good and excellent results were obtained after surgery, which is maintained
Table 2. SF-36 questionnaire results before and after bariatric surgery

\begin{tabular}{|l|c|c|c|}
\hline Variable & \multicolumn{1}{|c|}{$\begin{array}{c}\text { Pre-surgical } \\
\text { score } \\
(\mathbf{n = 9 8})\end{array}$} & $\begin{array}{c}\text { Post-surgical } \\
\text { score } \\
(\mathbf{n = 1 3 2})\end{array}$ & $p^{*}$ \\
\hline Median (IQR) & Median (IQR) & \\
\hline Physical function & $52.9(36.2-75)$ & $57(52-57.1)$ & 0.778 \\
\hline Physical role & $56.2(32-100)$ & $56.2(56.2-56.2)$ & 0.228 \\
\hline Bodily pain & $51.6(37-62.7)$ & $51.6(46.5-62.7)$ & 0.605 \\
\hline General health & $46.6(39.5-62)$ & $57.9(50.2-62.6)$ & $<0.001$ \\
\hline Vitality & $53.8(44.3-65.6)$ & $60.9(53.8-65.6)$ & 0.001 \\
\hline Social role & $57.1(46.3-87.5)$ & $57.1(46.3-57.1)$ & 0.001 \\
\hline Emotional role & $55.3(55.3-100)$ & $55.3(55.3-55.3)$ & $<0.001$ \\
\hline Mental health & $59.7(50-76)$ & $56.1(48.2-61.8)$ & 0.014 \\
\hline Physical component & $43(36-50.0)$ & $54.2(48.2-61.8)$ & $<0.001$ \\
\hline Mental component & $53.3(42.1-57.7)$ & $56.6(50.8-60.8)$ & 0.002 \\
\hline${ }^{*} \mathrm{p}<0.005$, Mann-Whitney's U-test. & &
\end{tabular}

for up to five years after surgery. In the BAROS questionnaire, QoL results were fair in 14 patients (10\%), good in $23(18 \%)$ and very good in 94 (72\%) (Fig. 1).

Regarding the assessment of comorbidities with the BAROS questionnaire, improvement was identified in eight patients $(6 \%)$, there were no changes in 13 (10\%), one major comorbidity was resolved and others improved in 18 patients (14\%) and all major comorbidities were resolved and others improved in 92 patients $(70 \%)$. Excess weight lost ranged from good to excellent and was correlated with the BAROS questionnaire score $(r=0.421 ; p<0.001)$. In the quality of life section, there was improvement in all components, except for the sexual component.

\section{Discussion}

This is one of the first studies to evaluate QoL in Mexican patients on a BS program or who have already undergone surgery, using the SF-36 and BAROS questionnaires. In our study, we observed that there was an improvement in QoL, predominantly in the physical component, which is consistent with the results of other investigations. ${ }^{13,14}$ This change might be related to an improvement in obesity-associated comorbidities and a significant weight loss. We observed a decrease in the score of the mental health domain, which could be influenced by non-evaluated factors, such as personality, 
Table 3. SF-36 questionnaire results comparison before bariatric surgery at different degrees of obesity vs. those of the healthy general population

\begin{tabular}{|l|l|c|c|c|c|}
\hline Health component & Domain & General population $(n=12)$ & BMI $40-50(n=123)$ & BMI $50-60(n=70)$ & BMI > 60 ( $(n=22)$ \\
\hline Physical & Physical function & $94.6 \pm 8.6$ & $54 \pm 18^{\dagger}$ & $49 \pm 11^{\dagger}$ & $53 \pm 15.6^{\dagger}$ \\
& Physical role & $94.5 \pm 15.4$ & $54.2 \pm 23^{\dagger}$ & $57.4 \pm 17^{\dagger}$ & $52 \pm 26^{\dagger}$ \\
& Bodily pain & $88.6 \pm 15.4$ & $52 \pm 17^{\dagger}$ & $53.5 \pm 14^{\dagger}$ & $50.2 \pm 13^{\dagger}$ \\
& General health & $72.9 \pm 15.5$ & $52.9 \pm 13^{\dagger}$ & $54.5 \pm 11^{\dagger}$ & $53.7 \pm 12^{\dagger}$ \\
\hline Psychological & Vitality & $81 \pm 11.6$ & $54.7 \pm 13^{\dagger}$ & $58.9 \pm 11^{\dagger}$ & $55.3 \pm 16^{\ddagger}$ \\
& Emotional role & $83.4 \pm 25.1$ & $54.5 \pm 22^{\dagger}$ & $56.4 \pm 20^{\dagger}$ & $64 \pm 25^{\dagger}$ \\
\hline Social & Mental health & $79.6 \pm 13.9$ & $55.8 \pm 13^{\dagger}$ & $56.9 \pm 15^{\dagger}$ & $58 \pm 15^{\dagger}$ \\
\hline
\end{tabular}

Vales are presented as means \pm standard deviation.

Obelisks indicate the significance of comparing each result with the general population: ${ }^{\dagger} p<0.001$, ${ }^{\ddagger} p<0.05$, Student's $t$-test.

\begin{tabular}{|c|c|c|c|c|}
\hline $\begin{array}{l}\text { Health } \\
\text { component }\end{array}$ & Domain & $\begin{array}{c}\text { General } \\
\text { population } \\
(n=12)\end{array}$ & Post-operated & $p^{*}$ \\
\hline \multirow[t]{5}{*}{ Physical } & $\begin{array}{l}\text { Physical } \\
\text { function }\end{array}$ & $94.6 \pm 8.6$ & $53.9 \pm 8.4$ & $<0.001$ \\
\hline & $\begin{array}{l}\text { Physical } \\
\text { role }\end{array}$ & $94.5 \pm 15.4$ & $53.5 \pm 8.8$ & $<0.001$ \\
\hline & Bodily pain & $88.6 \pm 15.4$ & $52.6 \pm 10.3$ & $<0.001$ \\
\hline & $\begin{array}{l}\text { General } \\
\text { health }\end{array}$ & $72.9 \pm 15.5$ & $55.7 \pm 8.4$ & $<0.001$ \\
\hline & Vitality & $81 \pm 11.6$ & $58.5 \pm 9.4$ & $<0.001$ \\
\hline \multirow[t]{2}{*}{ Psychological } & $\begin{array}{l}\text { Emotional } \\
\text { role }\end{array}$ & $83.4 \pm 25.1$ & $51.9 \pm 10$ & $<0.001$ \\
\hline & $\begin{array}{l}\text { Mental } \\
\text { health }\end{array}$ & $79.6 \pm 13.9$ & $54.2 \pm 10.2$ & $<0.001$ \\
\hline Social & $\begin{array}{l}\text { Social } \\
\text { function }\end{array}$ & $86.9 \pm 15.6$ & $52.4 \pm 9.9$ & $<0.001$ \\
\hline
\end{tabular}

eating disorders, depression, anxiety, personality disorders, aspects related to the social environment, self-esteem parameters and different expectations placed on bariatric surgery, among others. ${ }^{16}$

QoL physical and mental components have been observed to decrease as BMI increases, given that obesity causes or exacerbates different health conditions, which range from cardiovascular diseases to musculoskeletal pathologies, in addition to decreasing life expectancy in general. ${ }^{4}$ However, when the QoL of patients after surgery was compared with that of the healthy population, we observed low scores despite the BMI reduction, which suggests that obese patients continue to perceive that their physical and mental health is not adequate. It is possible that this perception is due to the fact that after the surgical procedure they continue on periodic follow-up with the doctor (which can be perceived as still being ill or being a "chronic" patient), or to the psychological stress caused by lifestyle changes, perception of the milieu, self-esteem, body image acceptance, or presence of skin flaccidity, among other factors. ${ }^{16,17}$ This lack of improvement to the levels reported in the general population has been observed in diseases with a chronic behavior such as diabetes, end-stage kidney disease, rheumatoid arthritis, and cancer. ${ }^{18}$ This is an important outcome to support long-term follow-up after surgery by a multidisciplinary team.

The BAROS questionnaire indicated excellent results in most cases. The authors consider that this is associated with physical improvement related to excess weight loss. On the other hand, the social, mental and sexual aspects addressed in the questionnaire do not have this improvement, which is consistent with other studies. ${ }^{10,15}$ As observed with our results, treatment of this chronic condition should be comprehensive before and after BC, addressing not only the physical and metabolic health condition, but also psychological aspects, which can influence on reincorporation to society, work and family life. As for the occupational aspect, most patients in our study were economically active young people. Kantarovich K. et al. ${ }^{19}$ observed that an increase in QoL two years after BS predicts an improvement in productivity and reduces work disability, 


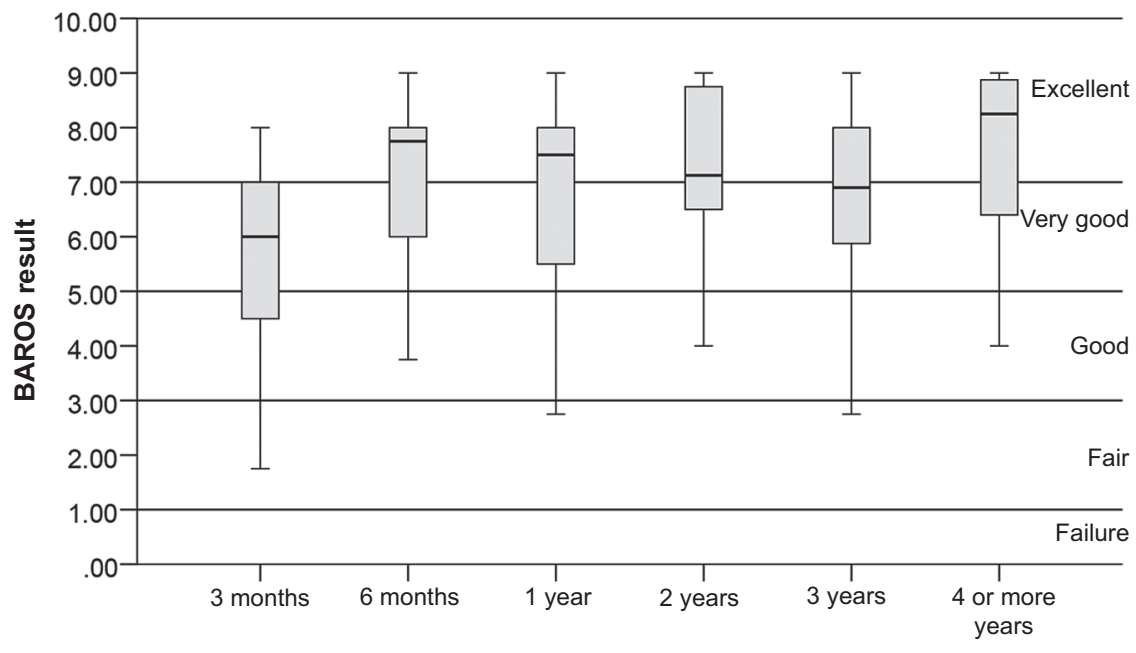

Time points at which BAROS result was determined

Figure 1. Results of the Bariatric Assessment Reporting Outcomes System (BAROS) Questionnaire. Results after surgery at different time points, from 3 months to 4 years, are shown.

so that all interventions aimed at supporting and maintaining QoL, especially those related to mental health in the postoperative period, will increase the improvement of work-related functioning.

In our study, $26 \%$ of the population had a preexisting psychiatric disorder, which may influence the results. Müller et al. observed that, four years after surgery, mental disorders were related to weight gain after it, ${ }^{20}$ similar to what we have previously found in our population. ${ }^{21}$ We consider that, even when in this study the percentage of excess weight lost within the first year was adequate (a decrease of more than $50 \%$ ), there is a lack of prospective studies evaluating the impact of depression, anxiety and quality of life in the long term, as well as their effects on weight regain, since these factors can influence on behavioral modifications, such as the need to perform physical activity, and adherence to the nutritional plan in the postoperative period. ${ }^{22}$

In the postoperative period, there are neuroendocrine changes (hypothalamic-pituitary axis), which are involved in the onset of emotional alterations; for example, reduction in the levels of neuropeptides from the gastrointestinal tract that regulate neuropeptide $Y$ central action, which are associated with the onset of depression and addictions and with an increase in the hedonic drive for food. ${ }^{23}$ There is still a lack of studies that combine sociological and psychological approaches with objective measures of food choices after BS. ${ }^{24}$

This study allowed us to evaluate BS results in terms of weight reduction, comorbidity improvement and QoL, which were similar to those reported in other international centers. In Mexico, obesity is a public health problem and access to BS is limited, given that few sites have a multidisciplinary team. Creation of new obesity clinics throughout the country is necessary, considering the benefits in terms of comorbidity remission, quality of life improvement in the physical and mental components, as well as mortality reduction in patients at productive age. These clinics should have a follow-up after BS, considering, in addition to improvements in clinical or biochemical parameters, QoL improvement, since information on the factors that determine QoL in Mexican patients is scarce.

One of the main limitations of the study is that, being a cross-sectional study, the populations are not being longitudinally compared against their own baseline results. However, so far, no other prospective study has evaluated QoL in Mexican patients. Nevertheless, baseline characteristics of the patients who underwent surgery are similar to those of patients before surgery, which suggests the possibility for the results to be applicable to all patients on similar conditions. The use of the BAROS questionnaire, designed only to evaluate the results after surgery and which does not require baseline assessment, also helps to assess whether postoperative quality of life results are concordant.

We should consider that the purposes of the questionnaires are not equivalent. The SF-36 questionnaire addresses quality of life from the patient physical and mental point of view, which can vary in a population or 
according to the disease, while BAROS gives significant weight to bariatric surgery technical results. Both are subject to adequate standardization, translation and application for their interpretation and we can observe how BAROS yielded good or excellent results for most patients in the short term, which are maintained at high ranges even in patients evaluated years after surgery, while SF-36 indicated that patients had a poor quality of life in all aspects prior to surgery, but that after the procedure they perceived an improvement in the physical, but not in the mental aspect.

Although carrying out a cohort study with these patients is necessary, with baseline and postsurgical questionnaires being applied, the number of patients required to achieve a significant sample for the follow-up time evaluated in this study would probably imply a significant investment of resources. This is one of the reasons why there are not many publications of this type in world literature.

\section{Conclusions}

Scores in the SF-36 and BAROS quality of life instruments in patients with severe obesity improved after bariatric surgery. However, despite the quick and persistent benefits of surgery, patients who underwent bariatric surgery had a poor quality of life, similar to what occurs in other chronic diseases.

\section{Conflict of interests}

The authors declare that they have no conflicts of interest.

\section{Funding}

The authors did not receive any sponsoring to carry out this article.

\section{Ethical disclosures}

Protection of human and animal subjects. The authors declare that the procedures that were followed adhered to the ethical standards of the responsible committee for experimentation on human beings and were in agreemant with the World Medical Association and the Declaration of Helsinki.

Confidentiality of data. The authors declare that they followed the protocols of their work center on the publication of patient data.
Right to privacy and informed consent. The authors obtained informed consent from the patients or subjects referred to in the article. This document is in the possession of the corresponding author.

\section{References}

1. World Health Organization [Internet]. Switzerland: Obesity and overweight 2015; 2020

2. Barquera S, Campos-Nonato I, Hernández-Barrera L, Pedroza A, Rivera-Dommarco JA. Prevalence of obesity in Mexican adults 20002012. Salud Publica Mex. 2013;55:S151-S160

3. Barrera-Cruz A, Rodríguez-González A, Molina-Ayala MA. The current state of obesity in Mexico. Rev Med Inst Mex Seguro Soc. 2013;51:292-299.

4. UlaHaq Z, Mackay DF, Fenwick E, Pell JP. Metalanalysis of the association between body mass index and health $\llbracket$ related quality of life among adults, assessed by the SFロ36. Obesity (Silver Spring); 2013;21:E322-E327.

5. Rivas A, Ocejo S, Sierra M. Evaluación de la calidad de vida en pacientes sometidos a cirugía de obesidad mórbida. Medicina Universitaria. 2009;11:243-246.

6. Chang CY, Hung CK, Chang YY, Tai CM, Lin JT, Wang JD. Health-related quality of life in adult patients with morbid obesity coming for bariatric surgery. Obes Surg. 2010;20:1121-1127.

7. Consenso Argentino de Nutrición en Cirugía Bariátrica. Argentina: Congreso Internacional de Cirugía Bariátrica y Metabólica; 2011.

8. Puzziferri N, Austrheim-Smith IT, Wolfe BM, Wilson SE, Nguyen NT Three-year follow-up of a prospective randomized trial comparing laparoscopic versus open gastric bypass. Ann Surg. 2006;243:181-188.

9. Favretti F, Cadiere GB, Segato G, Busetto L, Loffredo A, Vertruyen M, et al. Bariatric analysis and reporting outcome system (BAROS) applied to laparoscopic gastric banding patients. Obesity Surgery. 1998;8:500-504.

10. Velásquez-Zambarana JG, Miranda-Fontalvo A, Pulgar-Emanuelli MA Araujo-Zarate PS, Salazar-Maestre CJ. Evaluación de la calidad de vida en pacientes obesos y cirugía bariátrica. Rev Cienc Biomed. 2014;5:79-87.

11. Velarde-Jurado E, Ávila-Figueroa C. Evaluación de la calidad de vida. Salud Publica Mex. 2002:44:349-361.

12. Zúñiga MA, Carrillo-Jiménez GT, Fos PJ, Gandek B, Medina-Moreno MR. Evaluación del estado de salud con la Encuesta SF-36: resultados preliminares en México. Salud Publica Mex. 1999;41:110-118.

13. van der Hofstadt CJ, Escribano-Cubas S, Tirado-González S, Pérez-Martínez E, Ortiz Sebastián S, Estrada Caballero JL, et al. Evolución de la calidad de vida a los 24 meses de seguimiento en pacientes sometidos a cirugía bariátrica: comparación entre el bypass gástrico y la gastrectomía vertical tubular. In: Anales del Sistema Sanitario de Navarra. Spain: Gobierno de Navarra/Departamento de Salud; 2017

14. Raaijmakers LCH, Pouwels S, Thomassen SEM, Nienhuijs SW. Quality of life and bariatric surgery: a systematic review of short-and long-term results and comparison with community norms. Eur J Clin Nutr. 2017;71:441-449.

15. de Queiroz C, Sallet JA, de Barros e Silva PGM, de Souse-Queiroz LG, Pimentel JA, Sallet PC. Application of BAROS' questionnaire in obese patients undergoing bariatric surgery with 2 years of evolution. Arq Gastroenterol. 2017;54:60-64.

16. Peterhänsel C, Nagl M, Wagner B, Dietrich A, Kersting A. Predictors of changes in health-related quality of life 6 and 12 months after a bariatric procedure. Obes Surg. 2017;27:2120-2128.

17. Paul MA, Opyrchał J, Knakiewicz M, Jaremków P, Duda-Barcik $Ł$, lbrahim AM, et al. The long-term effect of body contouring procedures on the quality of life in morbidly obese patients after bariatric surgery. PloS One. 2020;15:e0229138.

18. Murillo YA, Almagro RM, Campos-González ID, Cardiel MH. Health related quality of life in rheumatoid arthritis, osteoarthritis, diabetes mellitus, end stage renal disease and geriatric subjects. Experience from a General Hospital in Mexico. Reumatol Clin. 2015;11:68-72.

19. Kantarovich, K, Wnuk S, Cassin S, Hawa R, Sockalingam S. Employment outcomes 2 years after bariatric surgery: relationship to quality of life and psychosocial predictors. Obes Surg. 219;29:2854-2861.

20. Müller M, Nett PC, Borbély YM, Buri C, Stirnimann G, Laederach K, et al. Mental illness has a negative impact on weight loss in bariatric patients: a 4-year follow-up. J Gastrointest Surg. 2019;23:232-238.

21. Cadena-Obando D, Ramírez-Rentería C, Ferreira-Hermosillo A, Albarrán-Sánchez A, Sosa-Eroza E, Molina-Ayala M, et al. Are there really any predictive factors for a successful weight loss after bariatric surgery? BMC Endocr Disord. 2020;20:20.

22. Gerlach G, Herpertz S, Loeber S. Personality traits and obesity: a systematic review. Obes Rev. 2015:16:32-63.

23. Morales-Medina JC, Dumont Y, Quirion R. A possible role of neuropeptide $Y$ in depression and stress. Brain Res. 2010;1314:194-205.

24. Hansen TT, Jakobsen TA, Nielsen MS, Sjödin A, Le Roux CW, Schmidt JB. Hedonic changes in food choices following Roux-en-Y gastric bypass. Obes Surg. 2016;26:1946-1955. 